\title{
ELECTROCARDIOGRAPHIC CHANGES DURING PRESSURE BREATHING
}

\author{
BY \\ R. J. SHEPHARD \\ From the RAF Institute of Aviation Medicine, Farnborough, Hants \\ Received May 10, 1956
}

It was recognized many years ago that the form of the electrocardiogram could be modified by a voluntary increase of breathing pressure, as during the Valsalva manœuvre (Kahn, 1909). During the early part of the second world war further studies were undertaken by German workers (Zettel and Fink, 1939; Müller, 1941), and it was found that it was altered even by the small fluctuations of breathing pressure associated with the wearing of a gas mask.

At the altitudes of interest to modern aviation physiology, quite high positive breathing pressures may be necessary for survival, and such pressures produce dramatic alterations (Howard et al., 1953; R.C.A.F., 1954), including occasional abnormalities of rhythm, and a consistent change in the standard limb leads interpreted as clockwise rotation (Howard et al., 1953) or more cautiously as right axis deviation (R.C.A.F., 1954). The alteration in electrical axis is of particular interest: it offers a new technique for analysing the theoretical background to certain features of the electrocardiogram, and may also provide objective evidence of the success with which various counterpressure garments maintain normal anatomical relationships during pressure breathing.

The present paper reports some measurements of the manifest electrical axis made during pressure breathing (with and without trunk counter-pressure) and during venous occlusion. Findings are correlated with other circulatory and respiratory changes observed during pressure breathing. The concept of a clockwise rotation of the heart in the frontal plane is confirmed, and it is concluded the electrocardiogram may indicate at least the order of this change.

\section{Methods}

Electrocardiographic Technique. Simultaneous recordings of the three principal leads were obtained in some observations, and in these it was possible to follow fluctuations in the electrical axis from beat to beat. In the remaining observations, single channel recording was used, tracings for different leads being obtained by repeating the pressure breathing after the elapse of a few minutes. The two methods gave closely similar results, although with the second method it was only possible to measure the mean axis over the course of one respiratory cycle.

The standard technique (Wood, 1950) has been used to calculate the momentary manifest electrical axis of the heart, the maximum upright QRS deflection being determined in leads I, II, III, and CV, which measures the potential of a point on the back (one inch to the left of the seventh thoracic vertebra) relative to Wilson's neutral electrode. Potential changes in the frontal plane have been displayed on a conventional triaxial reference system (Bayley, 1943). Approximate values for the horizontal plane have been calculated from the resultant of leads I and CV, and for the sagittal plane from the resultant of leads II . cos $30^{\circ}$ and CV. It seems clear from the detailed analysis of Frank (1954) that any attempt to estimate rotation in the horizontal and sagittal planes will be an approximation, and the above method of calculation was adopted on the grounds of simplicity rather than theoretical accuracy.

Muscle action potentials showed a marked increase during the course of pressure breathing. Their effect was minimized by the use of an appropriate filter throughout the experiments, but despite this, the precision of potential measurements was somewhat reduced during pressure breathing.

Subjects and Pressure Breathing Equipment. The subjects were four healthy young men, aged 20-26. 
All had considerable experience of pressure breathing. Observations were made with the subjects strapped in an "ejector seat". A pressure breathing helmet and in some instances counter-pressure garments were worn, the equipment being inflated from the compressed air supply via a constant-pressure demand regulator. The desired breathing pressure was attained within five seconds, and thereafter it showed only slight respiratory fluctuations (not more than $2-3 \mathrm{~mm} . \mathrm{Hg}$ ).

Changes of pulmonary blood volume during pressure breathing were estimated by a pressure-spirometer technique (Rahn et al., 1951). In the present observations, a conventional Knipping spirometer was "pressurized" by placing it in one lock of a decompression chamber. The end-tidal expiratory position and the expiratory reserve were recorded during normal quiet respiration and when pressure breathing, as illustrated in Fig. 1. Providing that subjects were able to expire maximally to at least the same chest volume when pressurized, the difference between the change of recorded end-tidal position and the change of expiratory reserve is an expression of alterations in the pulmonary blood volume during pressure breathing. ${ }^{*}$

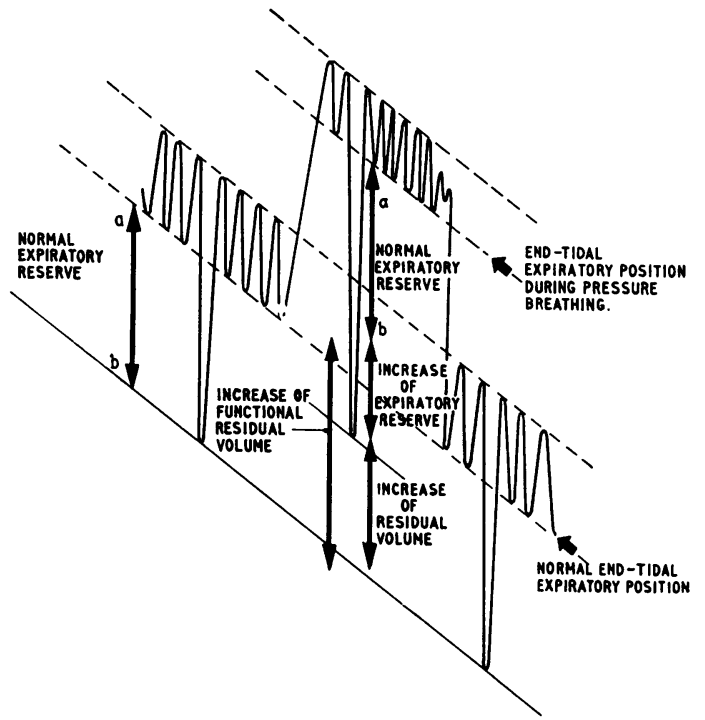

FIG. 1.-Alteration in pulmonary blood volume during pressure breathing. The amount is indicated by the difference between change of recorded endtidal expiratory position and change of expiratory reserve.

Venous Occlusion. Occluding cuffs around the thighs and arms were inflated to a pressure just below the diastolic level $(80 \mathrm{~mm}$. $\mathrm{Hg})$. The blood loss produced is of the following order: with cuffs on thighs only, $375 \mathrm{ml}$. after 5 minutes and $600 \mathrm{ml}$. after 10 minutes occlusion; with cuffs on thighs and arms, $555 \mathrm{ml}$. after 5 minutes and $860 \mathrm{ml}$. after 10 minutes occlusion. According to the data of Glaser and McMichael (1940), approximately one-half of this volume is derived from the pulmonary vessels.

Radiographic Measurements. Measurements of the cardiac axis, long and broad diameters, have been made in the manner suggested by Roesler (1937).

\section{RESULTS}

The Normal Electrical Axis of the Heart. Recent statistical studies (Kossman, 1953) have emphasized the wide range of absolute values for the cardiac axis. In the present small series, the greatest variation occurred in the frontal (coronal) plane, although there were also considerable inter-subject differences in the horizontal and sagittal planes.

* Fowler et al., 1951, claim to have proved the constancy of the expiratory chest position during pressure breathing; in fact, if account is taken of concomitant changes of residual volume, the expiratory volume is somewhat decreased. The method may therefore tend to under-estimate the change of blood volume. Inaccuracies could also arise from an alteration in the gas content of non-respiratory structures such as the osophagus. However, with the fixed visor headpiece this seems unlikely to be an important source of error. 


\begin{tabular}{l|c|c|c}
\hline Subject & $\begin{array}{c}\text { Frontal (coronal) } \\
\text { plane* }\end{array}$ & $\begin{array}{c}\text { Horizontal } \\
\text { plane }\end{array}$ & Sagittal plane* \\
\hline R.J.S. & $38 \cdot 7^{\circ}-57 \cdot 7^{\circ}$ & $17 \cdot 8^{\circ}-44 \cdot 2^{\circ}$ & $62 \cdot 0^{\circ}-74 \cdot 8^{\circ}$ \\
D.Pl. & $16 \cdot 3^{\circ}-30 \cdot 7^{\circ}$ & $27 \cdot 8^{\circ}-31 \cdot 0^{\circ}$ & $51 \cdot 6^{\circ}-57 \cdot 2^{\circ}$ \\
M.B. & $70 \cdot 3^{\circ}-74 \cdot 3^{\circ}$ & $43 \cdot 8^{\circ}-50 \cdot 4^{\circ}$ & $68 \cdot 6^{\circ}-70 \cdot 4^{\circ}$ \\
D.Py. & $79 \cdot 2^{\circ}-96 \cdot 3^{\circ}$ & & \\
\hline
\end{tabular}

* Degrees below horizontal plane. $\quad \dagger$ Degrees from frontal plane.

However, in any one subject, the mean direction of the cardiac axis was remarkably constant from day to day. In most complexes the $\mathrm{R}$ wave of lead I occurred a few milli-seconds prior to the $\mathrm{R}$ wave of leads II and III-a discrepancy that was noted by the earliest workers in this field (see Fahr, 1912). Careful measurements in subject D.Py. showed the differences in timing to average $63 \pm 4$ milli-seconds.

Normal quiet respiration produced a swing of $8-17^{\circ}$ in the frontal plane (clockwise during inspiration); rotation in the horizontal and sagittal planes were less than half as great. Counterpressure garments covering the entire trunk produced no significant change of electrical axis in the uninflated state. Garments covering the thorax produced only a small $\left(3-4^{\circ}\right)$ clockwise rotation in the frontal plane.

The Electrocardiogram during Pressure Breathing. All subjects showed a large clockwise rotation in the frontal plane. This developed quite rapidly, reaching a maximum value within 10-15 seconds. The rotation at 15 seconds showed some correlation with the breathing pressure (Fig. 2), but the relationship was not linear, little further rotation occurring at the higher breathing pressures. At these higher pressures, subjects found it increasingly difficult to prevent voluntary contraction of the thoracic muscles. Some rotation was also observed in the horizontal plane (backwards) and in the sagittal plane (clockwise).

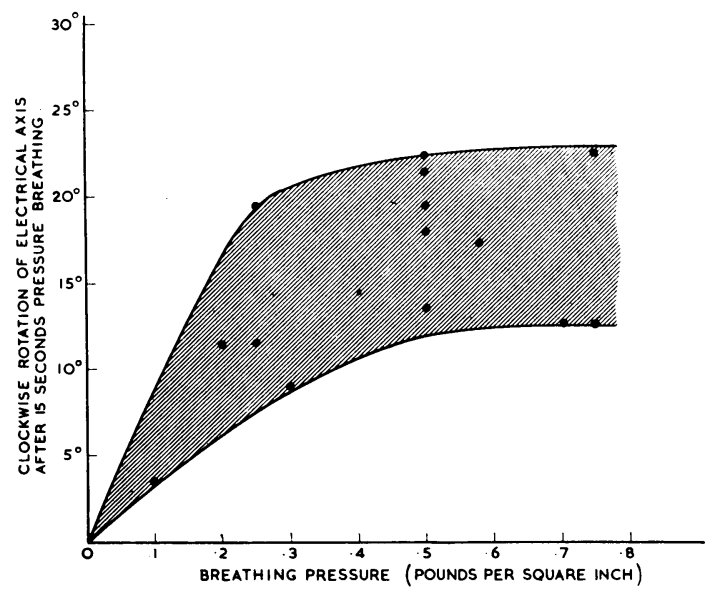

FIG. 2.-Rotation of the manifest electrical axis of the heart during pressure breathing (frontal plane). Four normal subjects.

\begin{tabular}{|c|c|c|c|c|c|c|c|c|c|c|}
\hline \multirow{2}{*}{\multicolumn{3}{|c|}{$\begin{array}{l}\text { Plane } \quad \cdots \quad \cdots \\
\begin{array}{c}\text { Breathing } \\
\text { pressure (P.S.I.) }\end{array}\end{array}$}} & \multicolumn{4}{|c|}{ Horizontal } & \multicolumn{4}{|c|}{ Sagittal } \\
\hline & & & $0 \cdot 1$ & $0 \cdot 25$ & 0.5 & 0.7 & $0 \cdot 1$ & $0 \cdot 25$ & 0.5 & 0.7 \\
\hline $\begin{array}{l}\text { M.B. } \\
\text { D.Pl. } \\
\text { R.J.S. }\end{array}$ & $\begin{array}{l}\ldots \\
\ldots \\
\ldots\end{array}$ & $\begin{array}{l}\ldots \\
\ldots \\
\ldots\end{array}$ & $\begin{array}{l}-6 \cdot 2^{\circ} \\
-0^{\circ} \\
-\end{array}$ & $\begin{array}{l}-8 \cdot 2^{\circ} \\
-0^{\circ} \\
-5 \cdot 4^{\circ}\end{array}$ & $\begin{array}{r}-21 \cdot 5^{\circ} \\
-0.5^{\circ} \\
-9 \cdot 8^{\circ}\end{array}$ & $\begin{array}{r}-14 \cdot 2^{\circ} \\
-7 \cdot 0^{\circ}\end{array}$ & $+2 \cdot 6^{\circ}$ & $\begin{array}{l}+4 \cdot 3^{\circ} \\
+7 \cdot 9^{\circ} \\
+3 \cdot 2^{\circ}\end{array}$ & $\begin{array}{r}+5 \cdot 0^{\circ} \\
+10 \cdot 5^{\circ} \\
+2 \cdot 9^{\circ}\end{array}$ & $\begin{array}{r}+9 \cdot 0^{\circ} \\
+10 \cdot 1^{\circ}\end{array}$ \\
\hline
\end{tabular}


The range of respiratory fluctuations was somewhat smaller during pressure breathing, despite an increased scatter in the direction of the resultant potential (Fig. 3). This finding may readily be related to the reduced tidal volume that is typical of positive pressure breathing, particularly during its early phases (Rahn et al., 1951; Shephard, 1956).

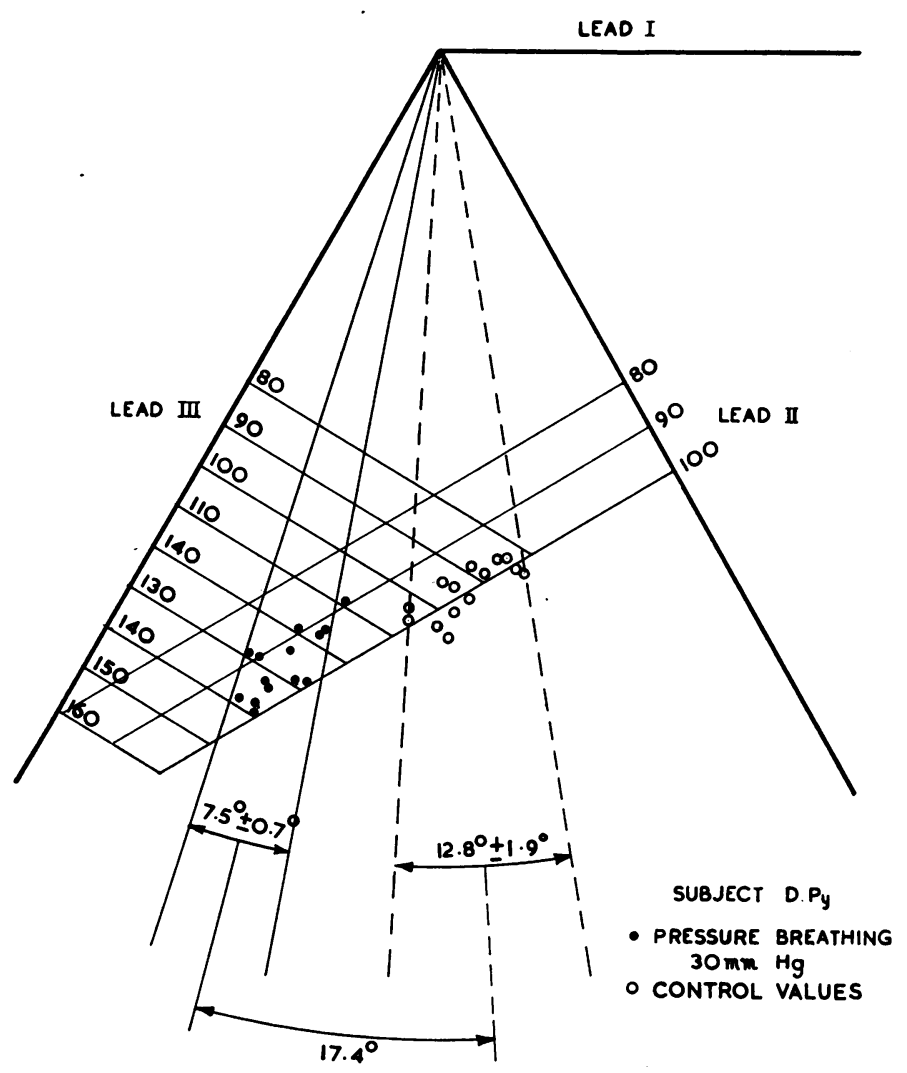

FIG. 3.-Triaxial reference system. To illustrate effect of pressurization on the electrical axis of the heart. There is a significant clockwise rotation $\left(17 \cdot 4^{\circ}\right)$, scatter in the direction of the resultant potential is increased, and the respiratory fluctuations are significantly decreased.

Two other important cardiographic changes are an increase of the $\mathrm{R}$ wave lag, and an alteration in the pulse rate. The $R$ wave phase change is small, but statistically significant. In D.Py. it amounted to $20 \pm 5$ milli-seconds. Changes of pulse rate differed in sign from subject to subject, and cannot therefore have contributed to the changes of electrical axis. In R.J.S., the pulse rate decreased with pressure breathing, this change being greater at the lower breathing pressures. Subject M.B. also tended to a fall of pulse rate at the lower pressures, but above 0.3 P.S.I. $(39 \mathrm{~mm} . \mathrm{Hg})$ there was a consistent rise of rate during pressure breathing. Subject D.Pl. showed an increase at all breathing pressures. Following release of the pressure, all subjects showed a sharp decrease of pulse rate that started within 2-3 seconds and reached a minimum after about 10 seconds-a minimum that was usually well below the normal resting level.

The Effect of Counter-pressure Garments. Rotational changes similar to those described above were noted, but a much higher breathing pressure was required to produce a given amount of rotation. The maximum effect was produced within 15-20 seconds, and if the pressure breathing 
was continued, the shift of axis sometimes showed a slight decrease. Detailed results for a typical garment providing counterpressure over most of the trunk and lower limbs again suggest that frontal rotation reached a limiting value of $20-25^{\circ}$.

\begin{tabular}{|c|c|c|c|c|c|c|c|c|c|c|c|c|}
\hline \multirow[t]{2}{*}{ Subject } & \multicolumn{4}{|c|}{ Frontal plane } & \multicolumn{4}{|c|}{ Horizontal plane } & \multicolumn{4}{|c|}{ Sagittal plane } \\
\hline & $\begin{array}{c}26 \\
(\mathrm{~mm} . \mathrm{Hg})\end{array}$ & 52 & 78 & 109 & 26 & 52 & 78 & 109 & 26 & 52 & 78 & 109 \\
\hline $\begin{array}{l}\text { D.Pl. } \\
\text { R.J.S. } \\
\text { D.Py. }\end{array}$ & $\begin{array}{l}+8 \cdot 4^{\circ} \\
+8 \cdot 5^{\circ}\end{array}$ & $\begin{array}{l}+18.3^{\circ} \\
+15 \cdot 0^{\circ}\end{array}$ & $\begin{array}{l}+19.7^{\circ} \\
+24.5^{\circ} \\
+24.7^{\circ}\end{array}$ & $\begin{array}{l}+8.0^{\circ} \\
+21.9^{\circ}\end{array}$ & $\begin{array}{l}+3.4^{\circ} \\
-3.4^{\circ}\end{array}$ & $\begin{array}{l}+1 \cdot 8^{\circ} \\
-8.6^{\circ}\end{array}$ & $-1 \cdot 8^{\circ}$ & $+1 \cdot 8^{\circ}$ & $\begin{array}{l}+4 \cdot 8^{\circ} \\
+2 \cdot 0^{\circ}\end{array}$ & $\begin{array}{l}+9.5^{\circ} \\
-0.8^{\circ}\end{array}$ & $+8 \cdot 8^{\circ}$ & $+10 \cdot 2^{\circ}$ \\
\hline
\end{tabular}

As in the experiments without chest counter-pressure, R.J.S. showed a consistent backward rotation in the horizontal plane, while in D.Pl. changes in this plane were small and variable. In the sagittal plane D.Pl. again showed a consistent clockwise rotation, while R.J.S. showed little change. A second type of counter-pressure garment (operating on the capstan principle) was also investigated in subject R.J.S.; rotation in the frontal plane was of a similar order $\left(7 \cdot 1^{\circ}\right.$ at $52 \mathrm{~mm}$., $12.3^{\circ}$ at $78 \mathrm{~mm}$. , and $17 \cdot 1^{\circ}$ at $99 \mathrm{~mm} . \mathrm{Hg}$ ).

With both forms of counter-pressure, respiratory fluctuations in the cardiac axis were rather less than at rest. The $\mathrm{R}$ wave phase lag was apparently slightly greater than in the experiments without counter-pressure, averaging $103 \pm 3$ milli-seconds at a breathing pressure of $78 \mathrm{~mm} . \mathrm{Hg}$ in subject D.Py. In all experiments, the pulse rate rose during the period of pressurization; the magnitude of this increase was related roughly to the applied pressure, subject R.J.S. showing a consistently greater response than D.P1. Following release of pressure, the pulse rate decreased as in the experiments without counter-pressure, but the fall was less precipitous, and the minimum value was usually little below the normal resting value.

Changes of Pulmonary Blood Volume. Measurements by the pressure-spirometer technique suggest that changes of pulmonary blood volume amounted to $400-500 \mathrm{ml}$. when a subject was provided with trunk counter-pressure.

\begin{tabular}{|c|c|c|c|c|}
\hline Subject & Breathing pressure & $\begin{array}{l}\text { Changes in recorded } \\
\text { end-tidal position }\end{array}$ & $\begin{array}{l}\text { Change of } \\
\text { expiratory reserve }\end{array}$ & Difference \\
\hline $\begin{array}{ll}\text { R.J.S. } & \cdots \\
\text { R.J.S. } & \cdots\end{array}$ & $\begin{array}{l}53 \mathrm{~mm} . \mathrm{Hg} \\
107 \mathrm{~mm} .\end{array}$ & $\begin{array}{l}773 \mathrm{ml} . \text { BTPS } \\
940 \mathrm{ml} .\end{array}$ & $\begin{array}{l}395 \mathrm{ml} . \text { BTPS } \\
395 \mathrm{ml} .\end{array}$ & $\begin{array}{l}378 \mathrm{ml} . \\
545 \mathrm{ml} .\end{array}$ \\
\hline
\end{tabular}

The volume of blood displaced seemed influenced to some extent by the state of the peripheral capacity vessels. If venous pooling in the lower limbs was restricted by the application of counterpressure (using a standard anti-G suit), a correspondingly smaller change of functional residual volume was observed.

\begin{tabular}{|c|c|c|c|c|c|}
\hline Subject & $\begin{array}{l}\text { Breathing } \\
\text { pressure }\end{array}$ & $\begin{array}{l}\text { Change of F.R.V. } \\
\text { without lower limb } \\
\text { counter-pressure }\end{array}$ & $\begin{array}{l}\text { Change of F.R.V. } \\
\text { with lower limb } \\
\text { counter-pressure }\end{array}$ & $\triangle$ & $\begin{array}{c}\text { Calculated reduction } \\
\text { in peripheral } \\
\text { pooling* }\end{array}$ \\
\hline $\begin{array}{l}\text { R.J.S. } \\
\text { D.PI. }\end{array}$ & $\begin{array}{l}53 \mathrm{~mm} . \mathrm{Hg} \\
53 \mathrm{~mm} .\end{array}$ & $\begin{array}{l}933 \mathrm{ml} . \text { BTPS } \\
663 \mathrm{ml} .\end{array}$ & $\begin{array}{l}773 \mathrm{ml} . \text { BTPS } \\
427 \mathrm{ml} .\end{array}$ & $\begin{array}{l}160 \mathrm{ml} . \\
236 \mathrm{ml} .\end{array}$ & $\begin{array}{l}165 \mathrm{ml} . \\
165 \mathrm{ml} .\end{array}$ \\
\hline
\end{tabular}

* This value has been calculated from the published pooling curves of Henry (1951) and Ernsting (1955), assuming that the lower limbs have a total volume of 20 litres, that counter-pressure is 75 per cent efficient, and that fluid filtration into the tissues has occurred for two minutes. 
The Effect of Venesection on the Electrical Axis of the Heart. A functional venesection of this order, produced over the course of ten minutes by means of occluding cuffs, had little effect on the electrical axis of the heart. With cuffs on the thighs, the only significant change seemed a small anticlockwise rotation in the frontal plane.

\begin{tabular}{|c|c|c|c|c|c|c|}
\hline Period of occlusion & . & $1-2 \mathrm{~min}$. & 3-4 min. & $5-6 \mathrm{~min}$. & $7-8 \mathrm{~min}$. & 9-10 min. \\
\hline $\left.\begin{array}{r}\text { Frontal } \\
\text { plane }\end{array}\right\} \begin{array}{l}\text { R.J.S. } \\
\text { D.Pl. }\end{array}$ &.. & $\begin{array}{l}+1.4^{\circ} \\
+1.5^{\circ}\end{array}$ & $\begin{array}{l}-0 \cdot 1^{\circ} \\
-2 \cdot 2^{\circ}\end{array}$ & $\begin{array}{l}-1 \cdot 9^{\circ} \\
-3 \cdot 7^{\circ}\end{array}$ & $\begin{array}{l}-1 \cdot 1^{\circ} \\
-4 \cdot 4^{\circ}\end{array}$ & $\begin{array}{l}-1 \cdot 0^{\circ} \\
-4 \cdot 5^{\circ}\end{array}$ \\
\hline $\left.\begin{array}{l}\text { Horizontal } \\
\text { plane }\end{array}\right\} \begin{array}{l}\text { R.J.S. } \\
\text { D.PI. }\end{array}$ & .. & $\begin{array}{l}-1 \cdot 0^{\circ} \\
-0.5^{\circ}\end{array}$ & $\begin{array}{l}+0.2^{\circ} \\
-0.4^{\circ}\end{array}$ & $\begin{array}{l}+0 \cdot 8^{\circ} \\
+1 \cdot 1^{\circ}\end{array}$ & $\begin{array}{l}+1 \cdot 2^{\circ} \\
+1 \cdot 2^{\circ}\end{array}$ & $\begin{array}{l}+0.7^{\circ} \\
+0.9^{\circ}\end{array}$ \\
\hline $\begin{array}{l}\text { R.J.S. } \\
\text { D.PI. }\end{array}$ & .. & $\begin{array}{c}-0 \cdot 1^{\circ} \\
0^{\circ}\end{array}$ & $\begin{array}{l}+0.7^{\circ} \\
-0.7^{\circ}\end{array}$ & $\begin{array}{l}+0.8^{\circ} \\
+0.4^{\circ}\end{array}$ & $\begin{array}{l}+1 \cdot 3^{\circ} \\
+4 \cdot 4^{\circ}\end{array}$ & $\begin{array}{l}+0.6^{\circ} \\
-1 \cdot 1^{\circ}\end{array}$ \\
\hline
\end{tabular}

With cuffs on both arms and thighs, a small clockwise rotation was observed, but even at the end of ten minutes it was in no way comparable with the changes observed during pressure breathing, being between $1^{\circ}$ and $3^{\circ}$ only.

Radiographic Changes during Pressure Breathing. Plates obtained before and after pressurization are illustrated in Fig. 4. The appearance is strikingly modified by pressurization. Measure-
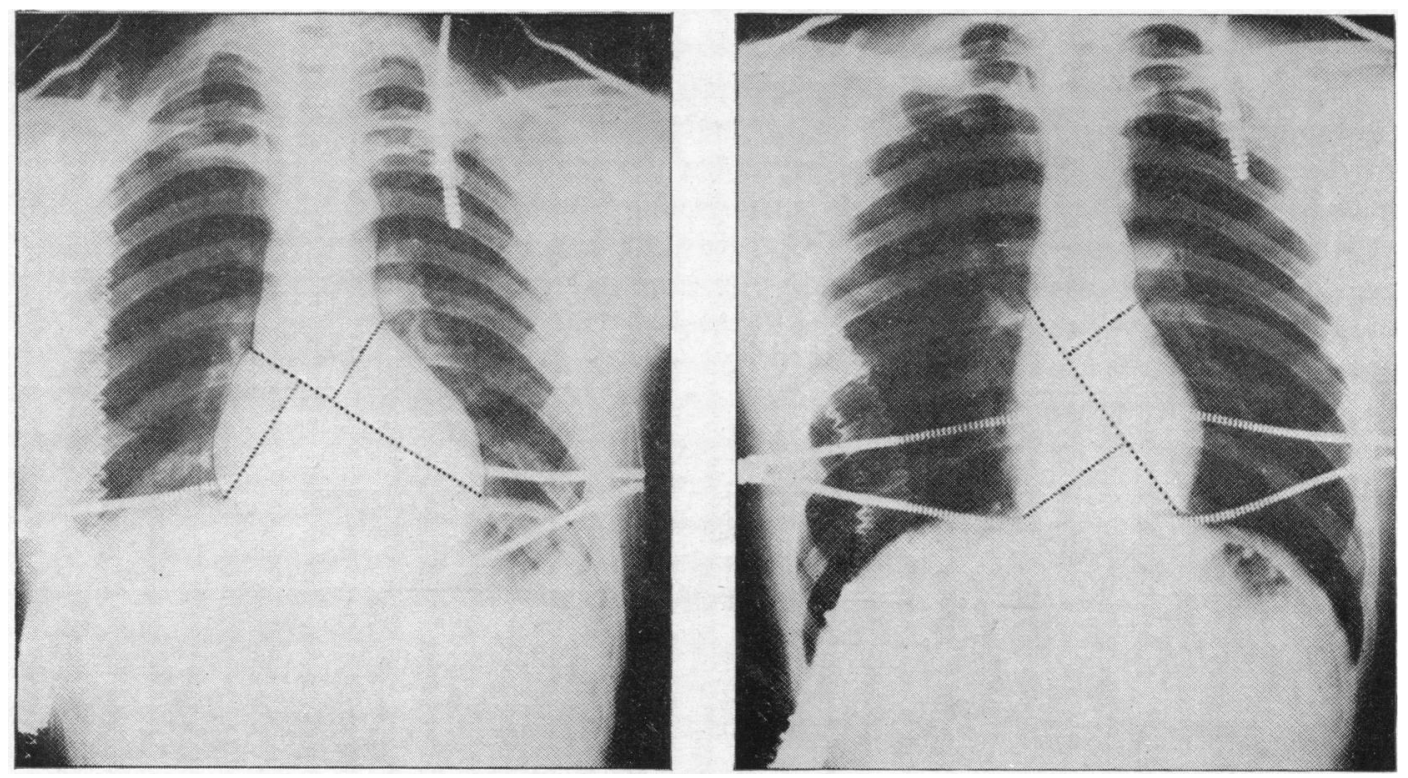

FIG. 4.-X-ray appearances before and after pressurization. Garment "A ", inflated to pressure of 1.5 p.s.i. $(78 \mathrm{~mm} . \mathrm{Hg})$. Long and broad diameters (Roesler, 1937) indicated by interrupted lines.

ment according to the method of Roesler (1937) shows the following changes when the garments were inflated to a pressure of $78 \mathrm{~mm} . \mathrm{Hg}$.

$\begin{array}{lcc} & \text { Garment " } A " & \text { Garment " B " } \\ \text { Change of long diameter } & -4.3 \% & -0.4 \% \\ \text { Change of broad diameter } & -7.5 \% & -7.4 \% \\ \text { Rotation in frontal plane } & 22^{\circ} & 6^{\circ}\end{array}$


It is difficult to measure changes of diaphragmatic level, owing to an increase in the angulation of the ribs, but it is clear that some descent occurs. In the region of the cardiac apex, it may be no more than $2-3 \mathrm{~cm}$., but laterally it is much greater, as shown by the considerable decrease of the costo-phrenic angles.

Changes on Functional Residual Volume. In subject R.J.S., changes of electrical axis with two forms of counter-pressure garment were found to be closely similar. It was therefore of some interest to compare changes of functional residual volume, using these same two garments. Again, very similar values were observed: in garment $A$, a pressure of $53 \mathrm{~mm}$. produced a change of $677 \mathrm{ml}$. (mean of 4 observations); in garment B, the change was $607 \mathrm{ml}$. at $27 \mathrm{~mm}$., $773 \mathrm{ml}$. at $53 \mathrm{~mm}$., and $940 \mathrm{ml}$. at $107 \mathrm{~mm}$. $\mathrm{Hg}$.

\section{Discussion}

It is now necessary to consider carefully how far the electrocardiographic changes noted above can be related to alterations in the anatomical axis of the heart.

Historical Evidence. The previous papers bearing on this problem have been concerned largely with absolute relationships between cardiographic and anatomical axes. Experimental conditions have often been rather remote from normal physiology, and while some authors have reported a close correspondence between the two axes, others have found considerable differences.

In the classical description of the method for determining the electrical axis (Einthoven et al., 1913), it was recognized that the technique was empirical and that potential changes recorded from the extremities could be influenced by many variables, including respiration, heart rate (affecting mainly the $\mathbf{P}$ and $\mathrm{T}$ waves), stroke volume of the two ventricles, and the electrical conductivity of the tissues surrounding the heart. Other inherent fallacies noted in more recent years are the assumptions of (1) an infinitely small cardiac dipole and (2) a homogeneously conducting body torso with no differences of potential between right and left legs. Despite these theoretical limitations, Einthoven and his contemporary Groedel (1912) concluded that the method was satisfactory in practice, and gave a reasonable agreement with radiographic estimates of the anatomical axis. More recent investigations have included the following.

(1) Generation of dipole current in the heart of the cadaver (Fahr and Weber, 1914; Wagner, 1924; Wilson, 1934). Under these conditions, Einthoven's triangle gave an indication of the electrical axis that was correct to within $3-4^{\circ}$, except in the direction that fluid had accumulated.

(2) Generation of a dipole current in externally placed thoracic electrodes (Wilson et al., 1949). This method showed a considerable discrepancy between the actual and calculated cardiac axes, but the results were largely invalidated by the abnormal position of the electrodes.

(3) Generation of a dipole current in the æsophagus (Abildskov et al., 1951). This method suggested a fairly close relationship between the true axis and that calculated from Einthoven's triangle.

(4) Generation of a dipole current in a homogeneous, fluid-filled torso (Frank, 1954). In this system, quite large departures from the equilateral triangle concept were found. However, it was admitted that the body conductivity differed by as much as 15 per cent from a homogeneous torso, and the results are therefore of limited application to the human subject.

(5) Burger and Milaan (1946) have described an improved torso where some allowance is made for the relatively poor conductivity of the lungs and spine, but the model is still of necessity rather crude, and cannot fully represent the dynamic changes of conductivity occurring in the human. With their model, potential changes could be represented by a triangle, but it tended to be isosceles rather than equilateral in shape.

It seems fair to conclude from this survey, that the precision of the relationship between anatomical and electrical axis is still undecided, largely on account of experimental difficulties.

Specific Problems during Pressure Breathing. Certain specific difficulties attend the measurement of electrical axis during pressure breathing. Of these, the most important is a possible alteration 
in the electrical conductivity of the viscera surrounding the heart. Einthoven et al. (1913) concluded that such changes did not contribute much to deviations of the electrical axis, since the magnitude of the resultant potential remained fairly constant. Katz and Korey (1935) and Lindner and Katz (1939) have challenged this conventional view. In a series of animal experiments, different aspects of the heart were insulated by a rubber diaphragm, and it was found that under these experimental conditions, a large part of the cardiac potential variations were conducted away from the posterior and inferior aspects of the heart, the air-containing portions of the lungs acting as insulators. Direct measurements of the specific resistance of the body have also shown that the trunk has a resistance about twice that of the limbs (Burger and Milaan, 1943), and this has again been attributed to the air content of the lungs. In the present study, the $R$ wave phase change suggests that the conduction path to the lower limbs is disturbed during pressure breathing, probably by the altered blood content of the dependent parts of the lungs. On the other hand, this change of pulmonary blood content does not seem responsible for the alteration in electrical axis, since if a similar change is produced by venous occlusion (admittedly at a slower rate) no material change of axis is observed. It may therefore be concluded that displacement of blood from the pulmonary vessels does not influence the validity of the method used to determine the cardiac axis.

Correlation with Other Measurements. It is not possible to determine cardiac rotation with any precision from X-ray plates, but these do serve to confirm the view that there is cardiac rotation of the order suggested by the electrocardiogram. A second and rather more precise comparison is afforded by the correlation between changes of functional residual volume and changes of electrical axis. Again, a satisfactory correspondence is found, both measurements suggesting that in subject R.J.S. two different garments afford a similar amount of counter-pressure.

It may be objected that the descent of the diaphragm is insufficient to permit cardiac rotation, but a simple trigonometrical calculation shows that if the heart pivots about the mid-line of the body, a descent of 2-3 cm. in the region of the cardiac apex would be quite adequate to produce a rotation of $20^{\circ}$. Further, assuming the diaphragm to have an average area of $270 \mathrm{sq} . \mathrm{cm}$. during quiet respiration, a descent of this order would increase the volume of the thorax by from 500 to $800 \mathrm{ml}$.- an amount that is quite compatible with direct measurements of this change. Descent of the diaphragm should be associated with a disturbance of the normal balance of pressures between pleural and peritoneal cavities, and there is some evidence that such a disturbance occurs during pressure breathing. While the pleural pressure follows the intra-pulmonary pressure to within 5-6 mm. Hg (Howard et al., 1953; Roxburgh et al., 1956), the intra-gastric pressure often lags as much as $10 \mathrm{~mm}$. $\mathrm{Hg}$ behind the increase of breathing pressure (Parry, unpublished observations).

Thus the changes of electrical axis are in keeping with observations made by a number of independent methods, and it may be concluded that the electrocardiographic method indicates at least the order of anatomical rotation of the heart that occurs during pressure breathing.

Significance of Cardiac Rotation. As has been noted, rotation is governed largely by the extent of diaphragmatic descent, and in the relaxed subject shift of the electrical axis is therefore one further measure of the efficiency of counter-pressure (particularly abdominal counter-pressure). However, it is less satisfactory than more direct methods of measurement, since a small diaphragmatic movement can initially produce considerable rotation, but further descent produces progressively less effect. It seems probable that the limiting value of $20^{\circ}-25^{\circ}$ rotation is due largely to this consideration, although one cannot exclude the possibility that the limit of diaphragmatic movement has been reached. There is no evidence to suggest that cardiac rotation of this order has any adverse effect on circulatory function, and indeed in the recorded cases of misadventure during pressure breathing, death has usually been secondary to pulmonary damage.

Changes of Thoracic Blood Content. Changes in the blood content of the heart and lungs also merit brief discussion. All previous measurements seem to have been made without trunk counterpressure. Methods have included the titre-board (Fenn et al., 1951), changes in the vital capacity following a Valsalva manœuvre (Bahnson, 1951) and measurements of the residual air (Fowler 
et al., 1951). These studies (mainly in the supine position) have shown that the volume of blood displaced is roughly proportional to the breathing pressure, a maximum of about $500 \mathrm{ml}$. being expressed within a few seconds at a breathing pressure of $30 \mathrm{~mm}$. $\mathrm{Hg}$. . Even allowing for differences between the sitting and supine positions, the present study suggests that a higher pressure is necessary to displace a given volume if trunk counter-pressure is provided, and that this difference is even more pronounced if counter-pressure is provided over the lower limbs.

The heart makes a significant contribution to the total alteration of thoracic blood content during pressure breathing. Referring to measurements of the cardiac silhouette, the decrease of broad diameter is considerably greater than the change of long diameter. This is because the broad diameter is decreased by concurrent backward rotation, while the long diameter is increased by clockwise rotation in the sagittal plane. The true change of diameter is somewhere between these two estimates-perhaps 6 per cent in garment A, and 4 per cent in garment B. From Roesler's figures (1937), the average cardiac diameter is $10-11 \mathrm{~cm}$., giving a total volume for the heart mass of some $500 \mathrm{ml}$. Calculation shows that if the diameter of this mass is reduced by 5 per cent, then the total volume decreases by approximately $75 \mathrm{ml}$. and neglecting small changes of muscle volume, it must be presumed that the heart sustains a blood loss of this order during pressure breathing.

\section{SUMMARY}

Positive pressure breathing produces a rotation of the manifest electrical axis of the heart. In the frontal plane, rotation occurs in a clockwise direction, reaching a limiting value of $20-25^{\circ}$ with increase of pressure. For a given pressure, rotation is less if trunk counter-pressure is provided.

There is an associated displacement of up to $500 \mathrm{ml}$. of blood from the heart and lungs, varying in amount with the breathing pressure and efficiency of counter-pressure. However, this does not seem responsible for the change of electrical axis, since a comparable change of blood volume produced by venous occlusion has little effect on the electrocardiogram. The blood loss from the dependent parts of the lung appears to do no more than slow the conduction of potential changes to the lower limbs.

There is sufficient agreement between changes of electrical axis, radiographic appearances, abdomino/pleural pressure gradients, and direct measurements of changes in functional residual volume to suggest that the electrocardiograph is indicating at least the order of anatomical rotation of the heart during pressure breathing.

Cardiac rotation appears related to descent of the diaphragm (probably through a cosine function), and is to this extent a measure of the efficiency of abdominal counter-pressure during pressure breathing. There is no evidence that rotation of the order noted has any adverse functional effect.

The author is indebted to Squadron Leader Howard for the X-ray plates, and to Flight Lieutenant Ernsting for one of the electrocardiograms.

\section{REFERENCES}

Abildskov, J. A., Burch, G. E., and Cronvich, J. A. (1951). Circulation, 2, 122.

Bahnson, H. T. (1951). Amer. Forces Tech. Rep. 6528, 518.

Bayley, R. H. (1943). Amer. Heart J., 26, 769.

Burger, H. C., and Milaan, J. B. van (1943). Acta med. Scand., 114, 584.

- - (1946). Brit. Heart J., 8, 157.

- - (1947). Brit. Heart J., 9, 154.

Einthoven, W., Fahr, G., and de Waart, A. (1913). Pflüg. Arch., 158, 275.

Ernsting, J. (1955). Flying Personnel Research Committee Rep. 926.

Fahr, G. (1912). Heart, 4, 147.

-, and Weber, A. (1914). Deutsch. Arch. Klin. Med., 117, 361.

Fenn, W. O., Otis, A. B., Rahn, H., Chadwick, L. E., and Hegnauer, A. H. (1951). Amer. Forces Tech. Rep., 6528, 38.

Fowler, R. C., Guillet, M., and Rahn, H. (1951). Amer. Forces Tech. Rep., 6528, 522. 
Frank, E. (1954). Circulation, 10, 101.

Glaser, E. M., and McMichael, J. (1940). Lancet, 2, 230.

Groedel, F. M. (1912). Die Röntgendiagnostik der Herz und Gefasserkrankungen, p. 68. Hermann Meuser, Berlin (Quoted by Einthoven et al., 1913).

Henry, J. P. (1951). J. Aviat. Med., 22, 31.

Howard, P., Jones, M., Roxburgh, H. L., Stewart, W. K., and Williams, K. G. (1953). Flying Personnel Research Committee Rep., 814, Part 3.

Kahn, R. H. (1909). Pflüg. Arch., 129, 291.

Katz, L. N., and Korey, H. (1935). Amer. J. Physiol., 111, 83.

Kossman, C. E. (1953). Circulation, 8, 920.

Lindner, E., and Katz, L. N. (1939). Amer. J. Physiol., 125, 625.

Müller, E. M. (1941) Zeit. ges. exp. Med., 109, 660.

Rahn, H., Otis, A. B., Chadwick, L., and Fenn, W. O. (1951). Amer. Forces Tech. Rep. 6528, 1.

Roesler, H. (1937). Clinical Roentgenology of the Cardiovascular System. London.

Royal Canadian Air Force. (1954). Institute of Aviation Medicine Rep. DRBS 5068-0-267.

Roxburgh, H. L., Ernsting, J., and Badger, P. J. (1956). Flying Personnel Research Committee Rep. 948.

Shephard, R. J. (1956). Flying Personnel Research Committee Rep. 963.

Wagner, G. (1924). Zentrabl. Herz-u. GeFasskr., 16, 1.

Wilson, F. N. (1934). Quoted by Wilson, Johnston, and Kossmann (1947). , Johnston, F. D., and Kossmann, C. E. (1947). Amer. Heart J., 33, 594.

-, Bryant, J. M., and Johnston, F. D. (1949). Amer. Heart J., 37, 493.

Zettel, H., and Fink, A. (1939). Klin. Wschr. I, 458.

Wood, P. (1950). Diseases of the Heart and Circulation. Eyre \& Spottiswoode, London. 